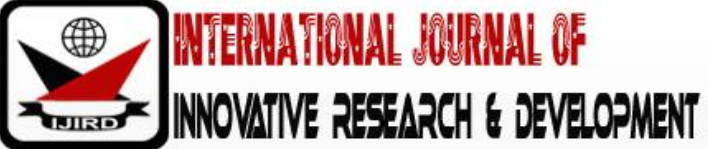

ISSN 2278-0211 (Online)

\section{Effects of Some Weather Elements and Irrigation on a Derived Polypots from Solid Wastes Used in Nigerian Dry-Land Commercial Nurseries}

\author{
Salami, Azeez Oyeniyi \\ Principal Research Fellow, Department of Upland Forest Research Station, \\ Forestry Research Institute of Nigeria
}

\begin{abstract}
:
Nursery experiments were conducted at Kano-Nigeria from June to May. The aim was to test the strength profile of the derived polypots obtained from the solid wastes of the discarded table water sachets produced in Nigeria, for massive production of seedlings towards plant development and general afforestation programmes. This was in view of earlier contention that the improvised polypots were not durable, and that they cannot stand the test of time for seedlings production. This was carried out by collecting the waste samples and exposing the sample specimen to some climate variables and irrigation, culminating into evolving a waste management strategy against environmental pollution, especially in the urban areas in Nigerian dry-land, as well as converting waste substances into productive values. Samples of the water sachets wastes were collected within Kano metropolis and were transformed as nursery polypots. There were 2 treatments, these are: (1) Samples of the table water sachets filled with potting mixture and exposed to natural weather vagaries with subsequent daily irrigation after the rainy period ( $\left.T_{1}\right)$. (2) Filled samples of water sachets exposed to the same condition but without subsequent irrigation $\left(\mathrm{T}_{2}\right)$. The experiments were put under observation during this period, while relevant data were collected on the rate of disintegration of the polythene materials. Results of the investigation however showed variations within the 2 treatments. Treatment 1 had the lowest mean disintegration record of 1 percent between the $11^{\text {th }}$ and $12^{\text {th }}$ months of the experiment. The result was then subjected to analysis using independent $t$-test. This also indicated that at 0.05 level of significance and 10DF, calculated $T$ was 1.1, while tabulated $T$ was 2.2. This conforms to the durability potentials of the discarded table water sachets (solid wastes) as another option of nursery polypots in Nigeria. The result of this study is however recommended hereby for massive seedlings production at all levels, especially in Northern Nigeria where we have limited rainfall, while the experiment is suggested for duplication in the south against the occurrence of green algae.
\end{abstract}

Keywords: Afforestation, environmental pollution, solid wastes, irrigation, weather vagaries, green algae.

\section{Introduction}

Polypots is one of the main components of the requirement with which seedlings are produced. It is the material through which seedlings are raised in the nursery for ease of tending before being moved to the site for woodlot, orchard, ornamental and aesthetic plantation establishments (Salami, 2003). The production of these seedlings is however central to any afforestation programme (Yahaya and Salami, 2008). Polypots also form the main backbone to the production of vigorous and healthy plant stocks, as well as supportive to the chances of establishing a good flora adornment to the commercial and qualitative values of plantation establishments (Otegbeye and Oje, 1995; Salami, 2006).

Polypots media had been utilized in several forms. The best medium however is the one that accommodates nursery seedlings in such a way as to ensure prompt germination, good growth and development, as well as permitting appropriate tending operations (Gbadebo and Salami, 2008). This should also not be prone to easy disintegration that would lead to the termination of lives of potted seedlings prematurely (Salami, 2006).

Several types of planting media also exist for use in the nursery for seedlings production towards woodlot plantation establishments, orchards, ornamentals and horticultural practices, or perhaps in a green house experiment. These include plastic buckets (perforated at the base especially for green house experiments), wooden boxes, trays, plantain wraps, bamboo, wooden canals (Fig. I); and the polythene medium which are of various sizes available in big, medium and small sizes (Jackson, 1974; ICUC, 2001).These polythene pots are usually black, and designed in Europe for the temperate regions, where solar radiation is limited (Salami, 2006).

The advent of the table water in sachets however in the early 90s, and the improvement in technology which brought about massive production of the commodity, as well as the consumption patterns of Nigerians, had resulted into an empirical solid waste generation in the urban environments of the country. The water sachet is one of the many solid wastes heavily generated in these urban centers, especially in the north, where sachet water is more consumed in the dry 
season. These turns out to be a gross nuisance and create pathetic management problems for its non degradable nature (Salami, 2006; Abarca Guerrero, et al, 2013), thereby causing great environmental concern (Salami, 2006).

Solid wastes however arise from unreasonable residuals in raw materials left over, rejected or scraps from processing plants or scrapped packaging materials, or even the soluble products themselves, when they are finally discarded (Read et.al. 1998). In

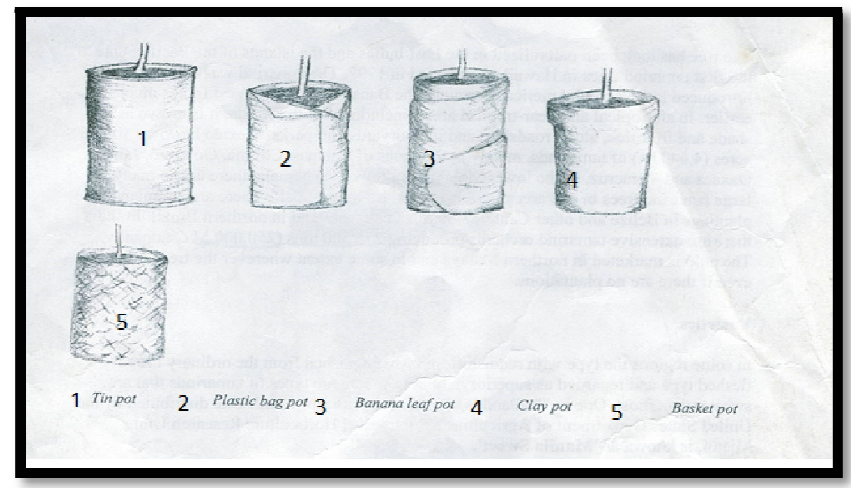

Figure 1: Types of Other Improvised Polypots Modified From: ICUC (2001)

general terms, wastes are movable materials that are perceived to be of no further value, and once discarded, may be no problem, or a nuisance, or a hazard according to Hill (1998).

However, in the late 80 s to early 90 s, the conventional black polypots for nursery activities was becoming scarce, and difficulties in financial allocation to end users from the relevant ministries and parastatals were becoming imminent. This was attributed to economic recession in the country, or perhaps the soaring cost of production of the polypot products, as reported by Salami (2006). In view of this, the innovation of the discarded table water sachet as another option of nursery polypots was brought about in a bid to continue massive seedlings production and plant propagation for general afforestation programmes, originating from Northern Nigeria. Moreover, this development has made the region to have the highest commercial nursery operators, as well as the highest seedlings producers for ornamentals, fruit trees; shade trees and woodlot plantation establishments (Ahmed and Salami, 2008), compared to other parts of the country in recent years (Salami, 2006).

None the less, considerable variation exists in the type of potting mixtures and polypots used in different nurseries in Nigeria and beyond (Lowe, 1966). This may be due to the variation of materials or rather due to prevailing tradition as reported by Jackson, et al, (1971). It may also be due to the taste and consumption patterns of the people (Salami, 2006). Moreover, the incorporation of polythene products for packaging consumables in Nigeria had been creating a lot of environmental problems, especially in the urban centre, as it is not biodegradable and takes several years to disintegrate in the soil when discarded.

In a developing economy like Nigeria however, where waste collection services had grossly been exhausted with uncontrolled dumpsites which are inadequately managed in view of gross inadequacies and negligence (Salami, 2006; Claire Swedberg, 2014); burning the polythene materials pollutes the environment, as well as contributing very immensely to the depletion of the ozone layer (Koko, 2003). Nonetheless, problems with governance also complicate the situation, as waste management in cities and urban centre is an ongoing challenge due to weak institutions, chronic underresourcing and rapid urbanization (UNEP, 2013; Claire Swedberg, 2014). This scenario is mostly associated with problems of inadequate skills, little or no formal education, little or no modern knowledge of agriculture, thereby becoming unemployed or underemployed, leading to increase in overcrowding, poverty, congestion, crime rate and other vices (Orojobi, et.al, 2008), especially as it affects the youths. The recycling process however is still in the embryonic stage in the country. This had generated a lot of interest in the environmental cycle, and the need to manage these polythene wastes for sustainable environmental utilization becomes inevitable.

In essence, it is very cheap, easier to work with and readily available for use as nursery polypots among other uses (Salami, 2006; Salami, et al, 2010), fig. 2, contrary to earlier antagonists' objections. Some people had literarily asserted that the improvised water sachet polypots were not suitable because they become brittle and break under intense sunlight. Others objected to its use because they say it promote algae growth and development. After over two decades of successful application and usage by the majority of Northern Nigerian forestry stakeholders for massive seedlings production, experimentation is hereby compelled to ascertain its durability potentials as nursery polypots in lieu of the harsh prevailing climatic conditions in the study area. 


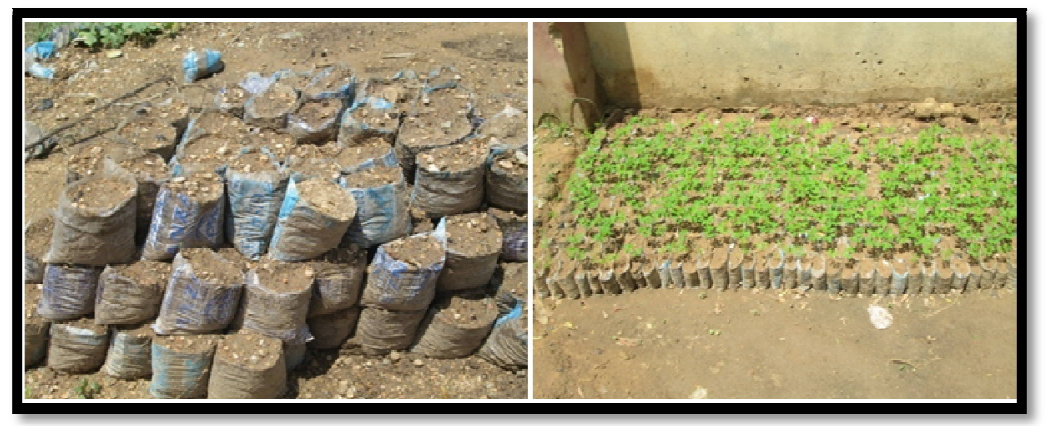

Figure 2: Derived Nursery Polypots under Utilization

The research is generally aimed at testing the strength profile of the discarded table water sachets, a solid waste used as nursery polypots by most commercial nurseries in northern Nigeria, at the same time evolving a waste management strategy against the indiscriminate presence of these sachets in our environment. The specific objectives however include the following: -

- Collection of samples of the waste materials for productive purpose

- Exposure of the experimental samples to various weather vagaries such as rainfall, sunlight, etc, alongside irrigation for durability potential test

- Collection of data from the experiment over specified time frame

- Analysis of the data collected for results and decision making and

- Appropriate recommendation of the results of findings on the experiment for public consumption.

\subsection{The Study Area}

The study was carried out within Kano State-Nigeria. The state is located in the North-West geo-political zone, with current population estimate of over 9 million people (Salami, 2014). Kano State occupies a land mass of about 20,131 $\mathrm{Km}^{2}$, on an approximate latitude $11.76^{\circ} \mathrm{N}$, and longitude $8.66^{\circ} \mathrm{E}$, (Abdulkadir, et al, 2013). Rainfall is between May and October, but stable for about 4 months between June and September, approximately 510-1140mm. per annum. Relative humidity is low and temperature varies between $14^{\circ} \mathrm{C}$ and $38^{\circ} \mathrm{C}$, typical of Sudan Savannah ecosystem, (Salami, 2003).

\section{Materials and Methods}

The main materials used in this experiment were the table water sachet solid wastes, and were collected within Kano metropolis, fig. III. Samples were collected in April, being the peak of the dry season when the sachet water is highly consumed. They were arranged after collection in hundreds and stored dry. These were properly scrutinized for chemical, mechanical, or physical damage, while good and neat ones were packed for the experiment. Sample processing however involves cleaning, opening and perforation to improvise them as nursery polypots.

\subsection{Pre-Treatment and Experimental Design}

The experiment had 2 samples (A and B) culminating into 2 treatments, i.e. Treatments 1 and 2 respectively. The 2 treatments were exposed to natural climatic factors as follows: - T1 - Samples that were exposed to supplementary watering once daily after the rains. T2 - Samples that were without any irrigation regime after the rains.

One hundred polypots were filled with potting mixture for each of the 2 treatments. They were arranged at random, 10 each between and within rows, while the experiment was monitored for a period of 12 months between June and May for assessment. Weeding through hand picking was however carried out at intervals on the 2 experimental treatments, with appropriate supplementary watering (on T1) where needed.

Data were collected and analyzed on bi-monthly disintegration basis i.e. 1-2, 3-4, 5-6, 7-8, 9-10, and 11-12 using percentage means and t-test for data analysis. Seedling introduction were however not required in the experiment and were not used.

\section{Results and Discussion}

Data were collected on both experiments at a couple of month's intervals. This is presented in Table 1. The results of the investigation indicated that there were differences in sample disintegration records at the 2 experimental levels between the $1^{\text {st }}$ and the $12^{\text {th }}$ months of the experiment. This is due to its exposure to various weather vagaries typical of seedlings production environment. The effects of irrigation and various weather vagaries on the experiment are hereby presented as follows: 


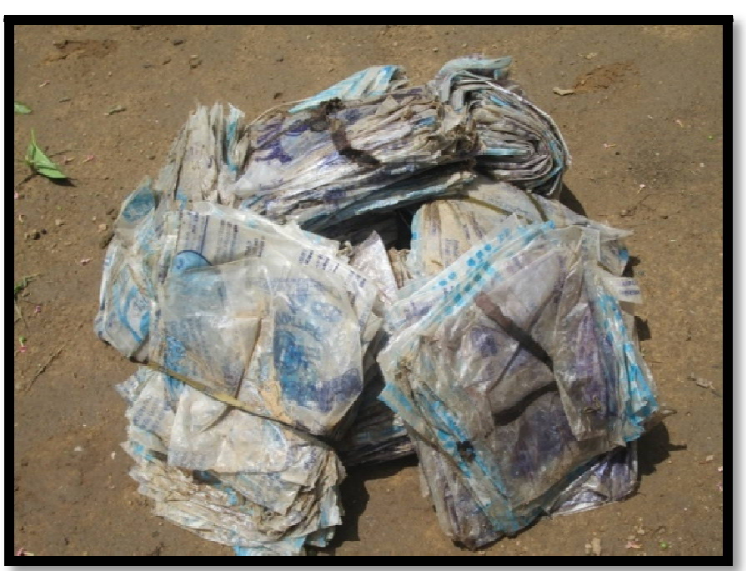

Figure 3: Derived Polypots Samples From Solid Wastes Used In Commercial Nurseries

\subsection{Effects of Irrigation on the Sachet Samples}

Treatment 1 which were samples of the table water sachets exposed to irrigation on daily basis after the rains showed a disintegration mean of only $1 \%$ at 11-12 months interval, whereas there was no disintegration at 1-2, 3-4, 5-6, 78- and 9-10-months intervals (see Table 1). This may not be unconnected with the fact that daily watering regimes as recommended in Provenzano (2007); Bentzen, et al, (2016) at periods without rainfall cools planting medium surface. This is typical of this treatment level, thus cooling the surface of the sachet samples at the event of the applied irrigation regime, while evaporation takes its source from the irrigation water which the samples always contain as a result of the daily irrigation regime, and not the water basement of the chemical composition of the polythene materials. Thus, their exposure to less fading out and disintegration as supported in Salami (2006) report. Other factor responsible for this result output may also be due to the fact that black surface traps heat energy and solar radiation is specifically lower on other surfaces, especially white, which is the predominant colour of the experimental samples. This is further analyzed by Nelkon (1977).

\subsection{Effects of Temperature and Solar Radiation}

Results in Treatment 2 where the water sachet samples were exposed to the same weather vagaries but no watering regime after the rainy season indicated a $4 \%$ and $16 \%$ mean disintegration records at 9-10- and 11-12-months intervals respectively. There were also no disintegration records at 1-2, 3-4, 5-6, and 7-8 months intervals. The results at this treatment level may largely be due to the fact that disintegration of samples occurred when the water molecules in the potting medium had all been evaporated into the atmosphere as a result of exposure to natural weather elements such as wind, tropical sunlight, temperature changes, etc, in view of vapour pressure as described by Nelkon (1977); Okeke and Anyakoha (2000).

\begin{tabular}{|c|c|c|c|c|c|c|}
\hline \multicolumn{7}{|c|}{ Months Intervals } \\
\hline Treatments & $1-2$ & $3-4$ & $5-6$ & $7-8$ & $9-10$ & $11-12$ \\
\hline 1 & 0 & 0 & 0 & 0 & 0 & 1 \\
\hline 2 & 0 & 0 & 0 & 0 & 4 & 16 \\
\hline SE- $^{+}$ & 0 & 0 & 0 & 0 & 0 & 7.6 \\
\hline
\end{tabular}

Table 1: Percentage Disintegration of Water Sachets at a Couple of Month's Intervals Subjected To Various Weather Vagaries and Irrigation

Subsequently, after the evaporation of the water molecules in the potting medium, the chemical composition of the polythene materials which is water based remains the next water molecules to be absorbed prior to the conversion of solar energy to heat energy, thereby resulting into fading out, cracking and disintegration at this treatment level; especially between the months of February and April when temperature and solar radiation is usually very high. This coincides with the month's intervals $9-10$ and $11-12$ of the experiment, which had a mean temperature of $35.7^{\circ} \mathrm{C}$ and $40.3^{\circ} \mathrm{C}$ respectively. Moreover, highest maximum temperature in the experimental year was recorded as $44{ }^{\circ} \mathrm{C}$ which also falls within the same period of highest sample disintegration in the month of April (Table 2). It was also the peak of the dry season when solar radiation is usually very high at the experimental area, having mean sunshine records for the months of February, March and April as 9.31, 7.5 and 8.2 hours per day respectively. (See Table 2). In a nutshell, sample disintegration in respect of the experiment is associated with high temperature and solar radiation in the absence of water/irrigation towards cooling effects. 


\begin{tabular}{|c|c|c|c|c|c|c|c|c|c|c|c|c|c|}
\hline \multirow[t]{2}{*}{ Month } & 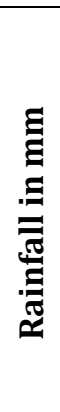 & \multicolumn{3}{|l|}{ 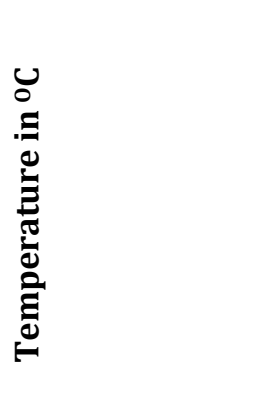 } & \multicolumn{3}{|c|}{ 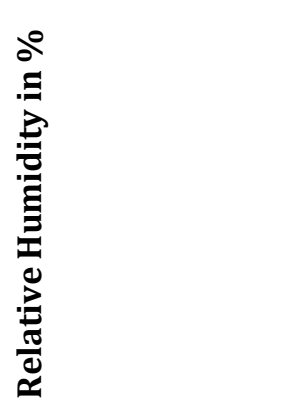 } & \multicolumn{3}{|l|}{ 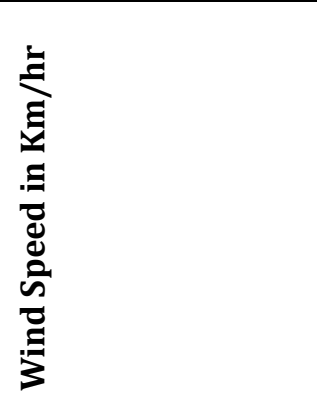 } & \multicolumn{3}{|l|}{ 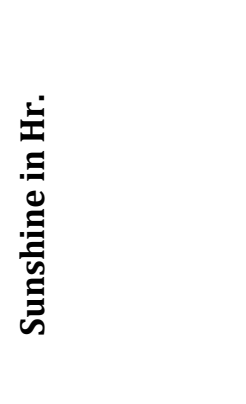 } \\
\hline & 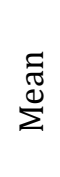 & 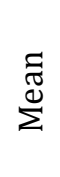 & 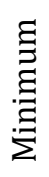 & 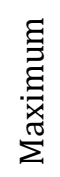 & 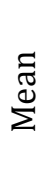 & 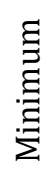 & 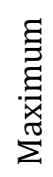 & 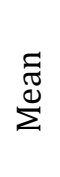 & $\begin{array}{l}\underset{\Xi}{\Xi} \\
\stackrel{\Xi}{\Xi} \\
\stackrel{\Xi}{\Xi}\end{array}$ & 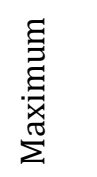 & 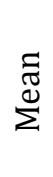 & 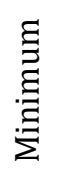 & 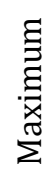 \\
\hline January & 0 & $\stackrel{+}{\rightarrow}$ & $\underset{7}{\sim}$ & 0 & $\stackrel{\sigma}{\underset{H}{H}}$ & $\stackrel{\rightrightarrows}{\exists}$ & 로 & $\underset{\sim}{\stackrel{\sim}{0}}$ & $\begin{array}{l}N \\
\text { in }\end{array}$ & $\begin{array}{l}\text { Na } \\
\text { ஸे }\end{array}$ & $\widehat{\sigma}$ & $\stackrel{\sim}{n}$ & 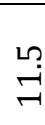 \\
\hline February & 0 & $\hat{\text { pे }}$ & $\stackrel{テ}{\sim}$ & 움 & $\begin{array}{l}\stackrel{\text { L }}{\llcorner} \\
\underset{+}{+}\end{array}$ & $\begin{array}{l}\text { L? } \\
\text { 웅 }\end{array}$ & $\stackrel{ }{\approx}$ & $\begin{array}{l}\stackrel{\Im}{]} \\
\underset{\exists}{G}\end{array}$ & $\begin{array}{l}\infty \\
\infty \\
\dot{m}\end{array}$ & $\underset{\stackrel{\Im}{\mathcal{H}}}{ }$ & ma & $\stackrel{0}{+}$ & $\stackrel{m}{\rightarrow}$ \\
\hline March & 0 & 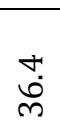 & $\underset{-1}{-1}$ & $\mathscr{q}$ & $\underset{ন}{\vec{ন}}$ & $\simeq$ & ڤે & $\stackrel{\vec{N}}{\sim}$ & 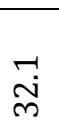 & $\begin{array}{l}\stackrel{m}{2} \\
\stackrel{2}{\sim}\end{array}$ & $\stackrel{\operatorname{Ln}}{\Lambda}$ & ţ' & \begin{tabular}{l}
$\infty$ \\
0 \\
\hdashline
\end{tabular} \\
\hline April & $\stackrel{\bullet}{\circ}$ & $\begin{array}{l}m \\
\stackrel{q}{q}\end{array}$ & $\vec{\sim}$ & $\stackrel{F}{F}$ & $\stackrel{m}{N}$ & $\hat{\overbrace{}}$ & 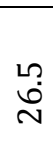 & $\begin{array}{l}\stackrel{2}{N} \\
\text { }\end{array}$ & 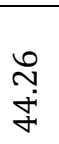 & 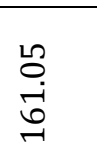 & $\underset{\infty}{\infty}$ & $\begin{array}{l}\infty \\
\dot{n}\end{array}$ & $\stackrel{+}{\leftrightarrows}$ \\
\hline May & $\underset{\text { Oे }}{\sim}$ & $\stackrel{\stackrel{H}{N}}{\stackrel{2}{n}}$ & 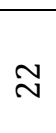 & $\mathcal{F}$ & 롬 & $\stackrel{\curvearrowright}{\stackrel{\sim}{\sim}}$ & $\begin{array}{l}\stackrel{L}{0} \\
\stackrel{\leftrightarrow}{0}\end{array}$ & $\begin{array}{l}\text { N̦ } \\
\text { n}\end{array}$ & $\begin{array}{l}\stackrel{0}{ } \\
\underset{+}{+}\end{array}$ & مُ & $\underset{\infty}{\sim}$ & $\stackrel{\infty}{m}$ & $\stackrel{+}{-}$ \\
\hline June & $\stackrel{0}{0}$ & $\vec{m}$ & $\stackrel{\infty}{\sim}$ & $\stackrel{\infty}{m}$ & $\stackrel{\widetilde{N}}{\widehat{N}}$ & $\stackrel{\sim}{\sim}$ & $\begin{array}{l}\text { Ln } \\
\text { ஜे }\end{array}$ & $\begin{array}{l}\stackrel{0}{ } \\
\stackrel{\sigma}{\sigma} \\
\Rightarrow\end{array}$ & $\begin{array}{l}\infty \\
\stackrel{+}{\leftarrow ்}\end{array}$ & $\begin{array}{l}\text { ñ. } \\
\underset{\sim}{ }\end{array}$ & $\stackrel{+}{\stackrel{\sim}{\sim}}$ & นึ? & $\underset{\sim}{\stackrel{I}{J}}$ \\
\hline July & 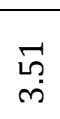 & 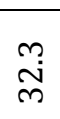 & $\stackrel{\sigma}{-}$ & $\stackrel{\text { n }}{m}$ & $\stackrel{\sim}{N}$ & 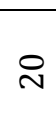 & $\stackrel{\curvearrowright}{\text { I }}$ & 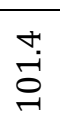 & $\begin{array}{l}\infty \\
\stackrel{\omega}{\omega}\end{array}$ & $\underset{\sim}{\vec{\pi}}$ & $\stackrel{\infty}{\stackrel{\sim}{-}} \underset{-}{-}$ & $\stackrel{-}{\rightarrow}$ & Э \\
\hline August & $\begin{array}{l}\infty \\
ٌ \\
\sigma\end{array}$ & $\vec{m}$ & $\stackrel{\sigma}{-}$ & mे & $\begin{array}{l}\text { ठै. } \\
\text { ָे }\end{array}$ & $\stackrel{\text { N }}{\stackrel{N}{N}}$ & $\stackrel{\text { L }}{\stackrel{\text { N }}{N}}$ & $\stackrel{\infty}{\vec{\sigma}}$ & $\stackrel{\sim}{ }$ & 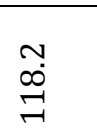 & $\underset{z}{\longleftarrow}$ & $\underset{z}{\longleftarrow}$ & 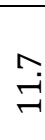 \\
\hline September & $\begin{array}{l}\hat{\text { ก̊ }} \\
\stackrel{\text { ㄱ. }}{2}\end{array}$ & $\begin{array}{l}\mathscr{b} \\
\text { H }\end{array}$ & $\stackrel{\sigma}{\rightarrow}$ & $\hat{m}$ & $\begin{array}{l}\tilde{\sigma} \\
\tilde{N}\end{array}$ & N & 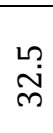 & $\begin{array}{l}\frac{L}{\hat{\sigma}} \\
\stackrel{\sigma}{\sigma}\end{array}$ & $\begin{array}{l}\text { L } \\
\stackrel{1}{-}\end{array}$ & $\begin{array}{l}\hat{\sigma} \\
\dot{x}\end{array}$ & $\stackrel{\stackrel{\curvearrowright}{N}}{N}$ & 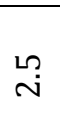 & $\begin{array}{l}\circ \\
\stackrel{0}{\infty} \\
\rightarrow\end{array}$ \\
\hline October & 0 & 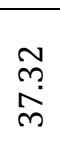 & 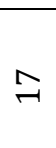 & के & $\begin{array}{l}\stackrel{\sim}{N} \\
\stackrel{\sim}{N}\end{array}$ & $\stackrel{m}{\stackrel{m}{-}}$ & $\stackrel{\leftarrow}{N}$ & 을 & $\begin{array}{l}\infty \\
\infty \\
\stackrel{\oplus}{\sim}\end{array}$ & $\begin{array}{l}0 \\
\text { oे } \\
\text { ᄋे }\end{array}$ & $\begin{array}{l}\text { Ln } \\
\infty\end{array}$ & $\underset{\sim}{\sim}$ & $\underset{\exists}{ت}$ \\
\hline November & 0 & $\stackrel{\check{N}}{\sim}$ & 우 & $\stackrel{+}{N}$ & $\underset{\stackrel{m}{\sim}}{\stackrel{m}{\sim}}$ & $\stackrel{\sim}{\underset{H}{+}}$ & $\ddot{N}$ & $\begin{array}{l}\sigma \\
\stackrel{1}{\infty} \\
\stackrel{\infty}{+}\end{array}$ & $\begin{array}{l}\text { హ. } \\
\text { L্ }\end{array}$ & స̃ & $\stackrel{m}{\stackrel{?}{+}}$ & 롬 & $\stackrel{\sim}{N}$ \\
\hline December & 0 & 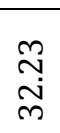 & $F$ & m & $\begin{array}{l}\stackrel{2}{m} \\
\underset{\forall}{+}\end{array}$ & $\begin{array}{l}\text { No } \\
\text { Oे }\end{array}$ & $\begin{array}{l}\sigma \\
\sigma \\
\sigma\end{array}$ & $\begin{array}{l}\stackrel{m}{+} \\
\stackrel{\text { Lे }}{n}\end{array}$ & $\stackrel{\sigma}{\tilde{N}}$ & $\begin{array}{l}\text { Na } \\
\stackrel{\infty}{二}\end{array}$ & $\underset{z}{\varangle}$ & $\underset{z}{\triangleleft}$ & $\stackrel{\longleftarrow}{\longleftarrow}$ \\
\hline
\end{tabular}

Table 2: Metrological Data for the Year 2017 in Kano NA: Not Available

Source: Kano State Agricultural and Rural Development Authority (KNARDA) 


\subsection{Effects of Rain Water}

With further analysis on Treatment 2, Adeleke and Leong (1980) epitomized that rain water, which the treatment samples had earlier fed on contains enough $\mathrm{CO}_{2}$ to make it a weak acid. It is further analyzed that in the tropical countries where heavy rainfall and warm climate (typical of the study areas, see Table 2) both promote chemical element composition; disintegration often proceeds very rapidly within the non organic complex. These led to the disintegration of the samples (which is non organic) after the exposure to the natural weather elements over time. The hypothesis is supported in Salami (2006) report.

\subsection{Effects of Repeated Temperature Changes}

Exposure to repeated temperature changes in view of the blazing tropical sunshine during the day makes the samples in Treatment 2 to be intensely heated. This causes the expansion of the outer layer of any such objects to make it crack and disintegrate from the top layer downward according to Adeleke and Leong (1980). Further analysis supported that at night, temperature usually drops very rapidly, especially at the upper outer layer of such inorganic objects, causing more rapid contraction, and setting up internal stresses (Adeleke and Leong, 1980). (See minimum and maximum temperature records at the experimental periods in Table 2). When this is repeated for months usually leads to disintegration as it occurred with the samples in Treatment 2 which cracked, tore and splitter from the $10^{\text {th }}$ month of the experiment, where minimum and maximum temperatures were recorded as $16^{\circ} \mathrm{C}$ and $43^{\circ} \mathrm{C}$ respectively (see tables I and II), which is also a month with very high temperature. This is corroborated in Salami (2006) report.

\subsection{Independent T-Test Analysis}

The results of the experiment were also subjected to t-test analysis to test for significant difference between the 2 treatments. At 0.05 level of significance, 10 degree of freedom (df), calculated $\mathrm{T}$ was 1.1 , while tabulated $\mathrm{T}$ was 2.2 . This designate the acceptance of the null hypothesis which indicated that there are no significant difference in the level of disintegration between the 2 samples, and that even at dry spell, the sachet solid wastes improvised as nursery polypots can yet support the life span of nursery seedlings before being taken to the field for plantation establishment. This is contrary to Onyewotu (2002) reports that the improvised polypots are no longer suitable because they become brittle and break under intense sunshine. It would however be seen that the sachet samples when used as nursery polypots did not indicate any sign of disintegration or breakage in the first 8 months which is enough a time for seedlings maturity even at a rain fed nursery without irrigation facilities.

\section{Conclusion}

The argument in respect of this experiment is not that the table water sachet is the best material as nursery polypots, but could be used as another option out of several others when massive seedling production is under consideration. Moreover, this work is appraising the use of a waste product for productive purpose, at the same time initiating a waste management strategy for sustainable environmental utilization. The materials are readily available, cheap, and easy to work with. They do not disintegrate or break under intense sunshine, but support the life span of seedlings production in the nursery before being taken to the field for planting out, once the necessary nursery tending like watering, weeding and other cultural and silvicultural practices are put in place. No green algae formation was also noticed throughout the experiment.

Moreover, the appearance of the discarded table water sachets for seedling production is beneficial in the generation of income at the lowest poverty level (Salami, 2006). Other benefits include:

- Increased nursery stock production at affordable costs.

- Geometric progression towards the establishment of private commercial nurseries, and resultant increase in multipurpose seedlings production.

- Tremendous check on environmental pollution caused by the littering of our urban environments with the water sachets.

\section{Recommendations}

All the above attributes indicate that the water sachets could be used as another option of nursery polypots, alongside a strategy towards the sustainable solid waste management for productive purpose. It is therefore and hereby recommended to the relevant stakeholders in forestry and agro allied sectors for massive multipurpose seedlings production especially in the dry-lands, while the experiment is suggested for replication in the rain forest zones to dwell further especially into the issue of green algae formation that may hamper its use as nursery polypots. Additionally, sachet collection centers are recommended to be put in place as a strategy for sustainable utilization without necessarily exposing the intending plant production and the users to any health detriment.

\section{References}

i. Abarca Guerrero, Lilliana; Maas, Ger; Hogland, William (2013): Solid waste management challenges for cities in developing countries. Waste Management. 33 (1): 220-232. doi:10.1016/j.wasman.2012.09.008. PMID 23098815.

ii. Abdulkadir, A., Usman, M.T., Shaba, A.H., and Saidu, S., (2013): An Appraisal of the Eco-climatic Characteristics in Nigeria. African Journal of Environmental Science and Technology. Vol. 7 (8), pp. 748-757.

iii. Adeleke, B.O. and G.C. Leong (1980): Certificate Physical and Human Geography for Senior Secondary Schools (New Impression). Oxford University Press, Ibadan. Pp. 133-134, 273. 
iv. Ahmed, R.U. and Salami, A.O. (2008): Propagative methods of Tamarindus species. Journal of Research in Agriculture. Vol. 5, No 1, pp.70-72.

v. Bentzen, Jeanet Sinding; Kaarsen, Nicolai; Wingender, Asger Moll (2016): Irrigation and Autocracy. Journal of the European Economic Association: n/a. doi:10.1111/jeea.12173. ISSN 1542-4774.

vi. $\quad$ Claire Swedberg (2014): Air-Trak Brings Visibility to Waste Management. RFID Journal. Retrieved April, 2019.

vii. Gbadebo, J.O. and Salami, A.O. (2008): Effects of pre-treatment on seed germination and seedling emergence of Tamarindus indica (Linn). Journal of Sustainable Environmental Management. Vol. I No. 1. Pp. 24-28. Published by Association of Women in Forestry and Environment (AWIFE).

viii. Hill (1998): in: BUK (2007): Course outline for postgraduate programme, Geography Department, Bayero University, Kano - Nigeria.

ix. ICUC (2001): Tsamiya in Hausa. A manual of the tamarind. International Centre for Underutilized Crops, Southampton, U.K. Pp. 21

x. Jackson, J.K. (1974): Nursery techniques in the savannah region of Nigeria. Research paper (Savannah series) No 32. Federal Department of Forestry Research. Ibadan. Pp. 6

xi. Jackson, J.K.; H.W. Branes and G.O.A. Ojo (1971): Experiments on nursery potting mixtures. Research papers No 7. Savannah Forestry Research Station, Samaru - Zaria, Nigeria in cooperation with FAO and UNDP. Pp. 4

xii. Koko, S. (2003): Our environment is going? Way out. A community development seminar project for NYSC, presented before the students and staffs of Audu Bako College of Agriculture, Dambatta - Kano, Nigeria in August.

xiii. Lowe R.G. (1966): Tour of irrigated forest nurseries in northern Nigeria. Department of Forestry Research Nigeria. Technical note No. 35. Pp. 7

xiv. Nelkon, M. (1977): Principles of physics. Longman Education International. Fifth edition. Pp. 248-249.

xv. Okeke, P.N. and M.W. Anyakoha (2000): Senior secondary physics (new edition). Macmillan Education Ltd. Pp. 220-224.

xvi. Onyewotu L.O.Z. (2002). 2nd quarter report. Forestry Research Institute of Nigeria, Shelterbelt Research Station, Kano, Nigeria.

xvii. Orojobi, J.O., O.O. Famuyide, and D.F. Omokore (2008): Rural youths training needs for poverty alleviation in two Local Government Areas of Kaduna State, Nigeria. Journal of Sustainable Environmental Management. Vol. 1 No 1 , pp. 17-23.

xviii. Otegbeye, G.O. and S.A. Oje (1995): Seed collection and handling activities of Savannah Forestry Research Station seed section, Forestry Research Institute of Nigeria, in: Forest Genetic Resources No 23, FA0 publications, Rome.

xix. Provenzano, Giuseppe (2007): Using HYDRUS-2D Simulation Model to Evaluate Wetted Soil Volume in Subsurface Drip Irrigation Systems. J. Irrig. Drain Eng. 133 (4): 342-350. doi:10.1061/(ASCE)0733-9437(2007)133:4(342)

xx. Read, et al, (1998): in: BUK (2007): Course outline for postgraduate programme, Geography department, Bayero University, Kano - Nigeria.

xxi. Salami, A.O. (2003): Phases of nursery development. Unpublished.

xxii. Salami A.O. (2006). Nursery polypots: the discarded table water sachet option. A project report for postgraduate programme. Bayero University, Kano, Nigeria. November Salami, A.O. (2014): Pre-germination Treatments of some Indigenous Sudan Savannah

xxiii. Tree Species in Nigeria. A Dissertation Report for M.Sc. Award. Department of Geography, Faculty of Earth and Environmental Sciences, Bayero University, Kano

xxiv. Salami, A.O., Adejoba, O.R., Gbadebo, J.O., and Salami, N.T. (2010): Application of the Discarded Table Water Sachets as Nursery Polypots and Its Roles Towards

xxv. Youth Development and Poverty Alleviation in Kano State, Nigeria. In: the

xxvi. Global Economic Crisis and Sustainable Renewable Natural Resources Management. L. Popoola (eds). Proceedings of the 33rd. Annual Conference of the Forestry Association of Nigeria held in Benin City Edo State, Nigeria. $25^{\text {th }}-$ 29th October, 2010. Vol. 1, pp. 542-549.

xxvii. UNEP (2013): Guidelines for National Waste Management Strategies Moving from Challenges to Opportunities (PDF). United Nations Environmental Programme. ISBN 978-92-807-3333-4.

xxviii. Yahaya, S.U. and Salami, A.O. (2008): An evaluation of pre-treatment on the germination of Tamarindus indica. Obeche Journal. Vol. 26 (2), pp.53-58. 